\title{
Comparison performance five level and seven-level cascaded H-bridge multilevel inverter of total harmonic distortion (THD)
}

\author{
L. Benyettou*, M. Tebbakh \\ Laboratory of Electrical Engineering, University of M'sila, Algeria
}

Corresponding Author Email: benyettou.loutfi_lge@yahoo.fr

https://doi.org/10.18280/mmc_a.910401

Received: 28 January 2018

Accepted: 15 April 2018

\author{
Keywords: \\ five levels inverter, seven-level inverter, \\ shunt active power filter, harmonic
} distortion, PWM control

\begin{abstract}
In this paper, we will study the performance of the three-phase parallel active filter topology based on the cascade bridge voltage inverter for the compensation of harmonics generated by the same non-linear load. In fact two topologies of the parallel active filter will be analyzed, that based on a voltage inverter with five levels of cascade bridge type and the other of the same type but with a seven-level inverter using the sinusoidal pulse width modulation PWM control techniques. We will focus particularly on the interest of the improvement of the waveform of the filter voltage compared to its reference, and consequently of the source currents, by carrying out simulations. Simulation results using PSIM simulator show a reduction in THD according to the standard IEEE-519 standard.
\end{abstract}

\section{INTRODUCTION}

The structure of the inverter with two voltage levels encounters physical and technological limits for the rise in voltage and therefore in power [1], in particular the quality of the voltage generated with a high harmonic rate (reference case sinusoidal voltage). It is to overcome these drawbacks that some researchers have introduced inverters having a multi-level voltage structure, and which generate a voltage closer to its reference, with fewer harmonics in the case where the voltage reference is sinusoidal [2].

A multilevel converter or multi-level converter can switch each input or output at least between three voltage or current levels [3]. In general, a multi-level inverter involves the combination of power semiconductors and capacitive voltage sources. The operation of this type of inverter is then based on the idea of distributing voltage (series) or current (parallel) constraints on the power switches so as to output voltage / current values at the output. higher [4-5]; this allows on the one hand to reduce the constraints on the electronic switches and on the other hand to improve the form of the voltage supplied by the inverter. Several researchers have proposed its application in the field of active filtering and reactive energy compensation [6-7].

In this article, we will study, in healthy mode, the topology of the three-phase parallel active filter based on the cascade bridge voltage inverter for the compensation of harmonics generated by the same non-linear load. In fact two topologies of the parallel active filter will be analyzed, that based on a voltage inverter with five levels of cascade bridge type and the other of the same type but with a seven-level inverter. We will focus particularly on the interest of the improvement of the waveform of the filter voltage compared to its reference, and consequently of the source currents, by carrying out simulations.

\section{CONCEPT OF MULTILEVEL CONVERTERS}

Multilevel converters include an array of semiconductor devices and capacitive voltage sources. By proper connection and control, they can generate a multiple-step voltage waveform with variable and controllable frequency, phase and amplitude. The stepped waveform is synthesized by controlling the switch devices to connect the load to the different capacitive voltage sources. Fig. 1 shows one phase of the converters with two, three and nine level output waveform [8]. The action of the semiconductors devices is represented by an ideal switch with several positions. A two-level converter generates an output voltage with two values (levels) with respect to the negative terminal $(\mathrm{N})$ of the capacitor, while the three level converter generates three voltages, and so on. It is observed that two-level converters can generate a variable frequency and amplitude voltage waveform by adjusting a time average of the two voltage levels, which is usually performed with pulse-width modulation (PWM) techniques. Multilevel converters have the voltage level as another control degree of freedom to generate the output waveform to obtain improved output waveform quality.

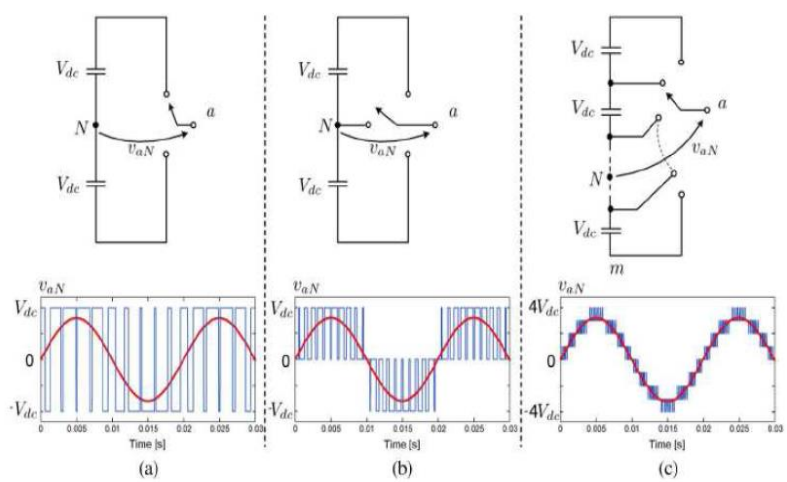

Figure 1. One phase leg of a converter with (a) two levels (b) three levels and (c) nine levels 
Contemporary research has evolved novel inverter topologies and unique modulation schemes. Moreover, three different major multilevel inverter structures have been reported in the literature. They are:

- Diode clamped /Neutral clamped Multilevel Inverter

- Flying capacitors /Capacitor clamped Multilevel Inverter

- $\quad$ Cascaded H-bridge Multilevel Inverter

\section{ACTIVE POWER FILTER DESCRIPTION}

Figure 2 presents the cascaded H-bridge Multilevel threephase shunt active power filter connected to balanced power grid (vsi for $\mathrm{i}=\{1,2,3\}$ ) powering a three phase diode rectifier feeding a variable values series $(\mathrm{R}, \mathrm{L})$ load. The active filter is composed, in each phase, of three voltage source H-bridge inverters ( $\mathrm{Hij}, \mathrm{i}=1,2,3, \mathrm{j}=1,2)$ with 4 bidirectional electronic switches (transistor + diode) for each one. The filter is connected to the power grid through inductive filter Lf for each phase.

The output currents of the shunt active filter are controlled to provide the identified reactive and harmonic currents generated by the non-linear load.

Several faulty cases can occur: power transistor or power transistor driver can be faulty. In each case, it results in the following models:

- A transistor is closed instead of being normally open. It results in a short-circuit of the DC voltage source. To isolate the faulty switch as fast as possible, one can use fuses.

- A transistor is open instead of being normally closed. The filter may continue injecting currents to the power supply. These currents don't cause any prompt risk because they are at the same range level as the case of no-fault condition. However, the filter, in this case, may pollute more the power supply instead of elimination of harmonic currents of nonlinear load. This case is considered in this paper.

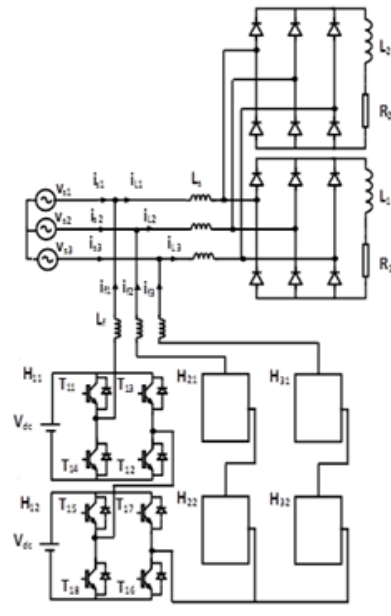

a) APF at 5 levels

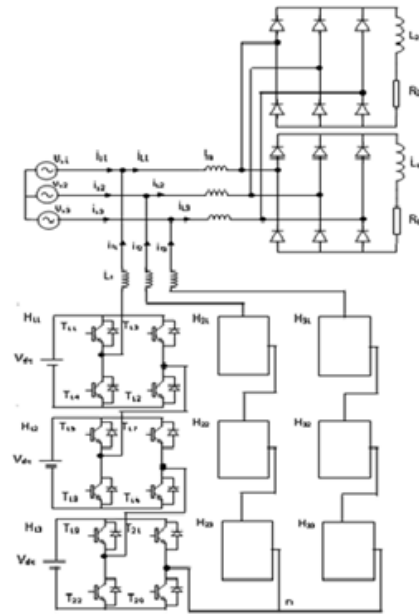

b) APF at 7 levels
Figure 2. Cascaded H-bridge multilevel three-phase shunt active power filter topology [9-10]

\subsection{Harmonic current identification}

Figure 3 presents a block diagram of the proposed control system. The major advantage of this control principle is its simplicity and easiness to be implemented. The task of this control is to determine the current harmonic references to be generated by the active filter.

They are defined using classical active and reactive power method proposed by Akagi [11].

By supposing that the main power supply voltages are sinusoidal, current harmonic references will be calculated like indicated in [12].

$(\alpha, \beta)$ voltage components at coupling point of active filter $(v \alpha, v \beta)$ and currents $(i \alpha, i \beta)$ are defined by the classical Concordia transformation:

$$
\left[\begin{array}{l}
x \alpha \\
x \beta
\end{array}\right]=2 / 3\left[\begin{array}{ccc}
1 & -1 / 2 & -1 / 2 \\
0 & -\sqrt{3} / 2 & \sqrt{3} / 2
\end{array}\right]\left[\begin{array}{l}
x 1 \\
x 2 \\
x 3
\end{array}\right]
$$

where $x=\{v, v s, i, i L\}$

The instantaneous real and imaginary powers, noted by $\mathrm{p}$ and $\mathrm{q}$, are calculated by:

$$
\left[\begin{array}{l}
p \\
q
\end{array}\right]=\left[\begin{array}{cc}
v \alpha & v \beta \\
-v \beta & v \alpha
\end{array}\right]\left[\begin{array}{l}
i \alpha \\
i \beta
\end{array}\right]
$$

These powers are then filtered by high-pass filters, which gives ph and qh and the harmonic components of the currents will be:
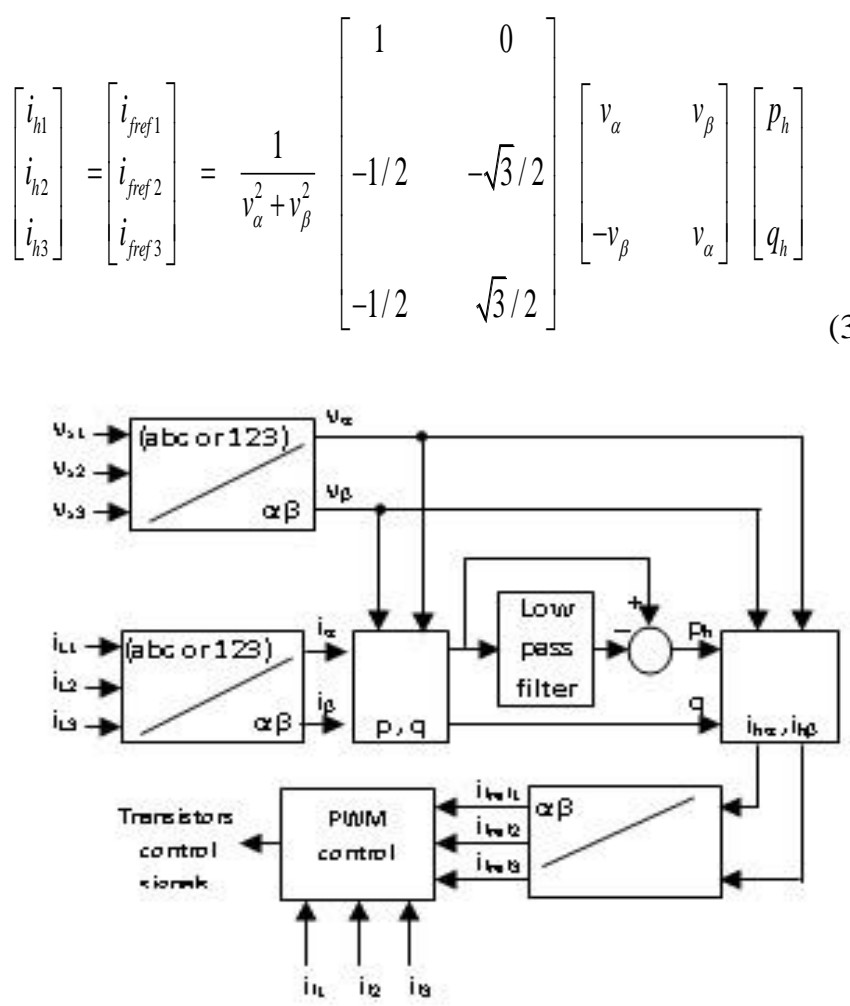

Figure 3. Block diagram of the harmonic currents identification 


\subsection{PWM control of the APF at 5 and 7 levels}

The purpose of the control at PWM is to generate the opening and closing orders of the switches so that the current of the active filter is closest to its reference. The natural sampling PWM control scheme is illustrated in Figure 4. In this method, the difference between the reference current $I_{r e f}$ and the current of the filter $I_{\text {filter }}$ is applied to the input of a regulator. The output signal of the regulator, called the modulator, is then compared to a triangular signal of fixed and sufficiently high frequency (carrier) in order to determine the switching orders of the switches [13-14]

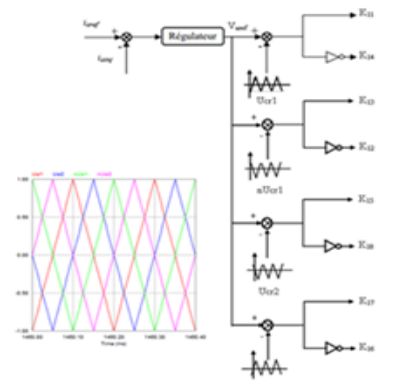

a) PWM control of the APFat 5 levels

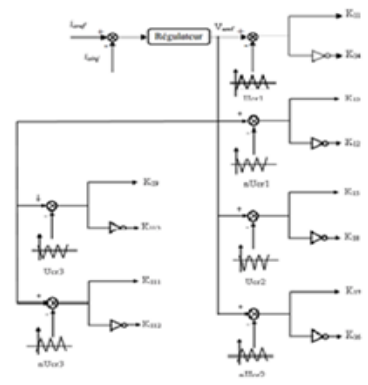

b) PWM control of the APF at 7 levels

\section{RESULTS OF THE SIMULATION}

To evaluate the performance of the parallel active filter based on a voltage inverter at five and seven levels, we proceeded to the simulation of the association Grid balancedpolluting load (rectifier PD3 with diodes) -APF, while adopting the instantaneous real and imaginary powers method for the identification of harmonic currents, as well as the control by hysteresis regulators to control the APF inverter. The simulation of the global system is performed under the PSIM environment. During simulations, the pollutant load consists of two diode PD3 three-phase rectifier bridges and the supply network is a balanced, unpolluted three-phase network. The power supply is modeled by phase by a f.e.m. sinusoidal in series with inductance Lc characterizing the short circuit impedance of the network. Rectifiers charge in two RL loads. The inductance Ls at the input of the rectifiers models the line impedance and any additional inductances implemented to limit sudden changes in current. The parallel active filter is composed of a two-level voltage inverter with a fixed DC voltage source (non-autonomous active filter) and a filtering inductance Lf.

The parameters with which the 5 and 7 level inverter-based APF was simulated are shown in the Table 1.

Figure 4. PWM control principle of phase 1 APF current based on 5 and 7 level voltage inverter in cascade bridge

Table 1. Simulation parameters for a voltage inverter-based active parallel filter in 5 and 7 level cascade bridges

\begin{tabular}{|c|c|c|}
\hline \multicolumn{2}{|r|}{ Parameter } & Numerical value \\
\hline \multirow{3}{*}{ Electrical network } & $\mathrm{E}_{\mathrm{s}}$ & $220 \mathrm{~V}$ (simple effective value) \\
\hline & Frequency f & $50 \mathrm{~Hz}$ \\
\hline & Inductance $\mathrm{L}_{\mathrm{s}}$ & $0.0015 \mathrm{H}$ \\
\hline \multirow{4}{*}{ Interference load (pollutant) } & Resistance $R_{l}$ & $\begin{array}{l}\mathrm{R}_{1}=10 \Omega \text { for } \mathrm{t} \epsilon[0,0.7] \mathrm{sec} \\
\mathrm{R}_{1}=5 \Omega \text { for } \mathrm{t} \epsilon[0.7,1.5] \mathrm{sec}\end{array}$ \\
\hline & Inductance $\mathrm{L}_{1}$ & $0.005 \mathrm{H}$ \\
\hline & Resistance $R_{2}$ & $\begin{array}{l}\mathrm{R}_{2}=1000 \Omega \text { for } \mathrm{t} \epsilon[0,1.1] \mathrm{sec} \\
\mathrm{R}_{2}=5 \Omega \text { for } \mathrm{t} \epsilon[1.1,1.5] \mathrm{sec}\end{array}$ \\
\hline & Inductance $\mathrm{L}_{2}$ & $0.01 \mathrm{H}$ \\
\hline \multirow[b]{2}{*}{ Parallel active filter } & Inductance $\mathrm{L}_{f}$ & $0.004 \mathrm{H}$ \\
\hline & Voltage Vdc (E) for each bridge & $\begin{array}{l}400 \mathrm{~V} \text { at } 5 \text { Level } \\
250 \mathrm{~V} \text { at } 7 \text { Level }\end{array}$ \\
\hline \multirow[b]{3}{*}{ PWM Control } & Gain PI regulators from APF currents & 0.05 \\
\hline & Time constant of the PI regulators of the currents of the APF & 0.0001 \\
\hline & Frequency of the carrier & $\begin{array}{c}5000 \mathrm{~Hz}=5 \mathrm{Khz} \text { at } 5 \mathrm{Level} \\
2500 \mathrm{~Hz}=2.5 \mathrm{Khz} \text { and } 5 \mathrm{Khz} \text { at } 7 \\
\text { Level }\end{array}$ \\
\hline \multirow{3}{*}{$\begin{array}{l}\text { 2nd order low pass filter } \\
\text { (identification of current } \\
\text { harmonics by the instantaneous } \\
\text { real and imaginary powers } \\
\text { method) }\end{array}$} & Low pass filter gain & 1 \\
\hline & Cutoff frequency of the low-pass filter & $15 \mathrm{~Hz}$ \\
\hline & Damping coefficient the low-pass filter & 0.7 \\
\hline
\end{tabular}

\section{INTERPRETATION OF RESULTS}

Figure 5 shows the three-phase voltage of the electrical network. It is considered balanced and not significantly disturbed by the current of the polluting load. The latter is shown in Figure 6 while its harmonic spectrum is shown in Figure 7 for two different loads. We note the presence of harmonic components of rank 5, 7, 11, 13, 17, 19 whose frequencies are $250 \mathrm{~Hz}, 350 \mathrm{~Hz}, 550 \mathrm{~Hz}, 650 \mathrm{~Hz}, 850 \mathrm{~Hz}, 950$ $\mathrm{Hz}, \ldots$. The harmonic distortion rate of the phase 1 current of the pollutant load varies $(22.95,19.1,14)$ according to the variation of the values of the continuous loads supplied by the rectifiers, as shown in Figure 8.

Figure 9 illustrates the waveforms of the three-phase harmonic currents identified by the instantaneous real and imaginary power method accompanied by the currents injected by the parallel active filter based on a 5-level voltage inverter. There is good agreement of the harmonic current identified and the current of the APF for each phase. This led to a quasisinusoidal mains current (Figure 10) where the harmonic 
components of order $h=6 \mathrm{~K} \pm 1$ are significantly reduced (Figure 11) and the THD is reduced to less than 2\% (Figure 12).

Figure 13 illustrates the waveforms of the three-phase harmonic currents identified by the instantaneous real and imaginary power method accompanied by the currents injected by the parallel active filter based on a 7-level voltage inverter.
Note the good continuation of the current of the APF with respect to the harmonic current identified for each phase. This produced a quasi-sinusoidal mains current (Figure 14) where the harmonic components of order $\mathrm{h}=6 \mathrm{~K} \pm 1$ are significantly reduced (Figure 15) and the THD is reduced to less than $2 \%$ (Figure 16).

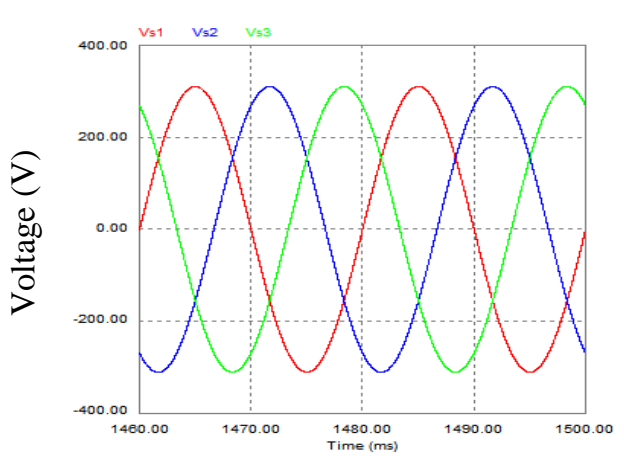

Figure 5. Three-phase voltage of the electricity network
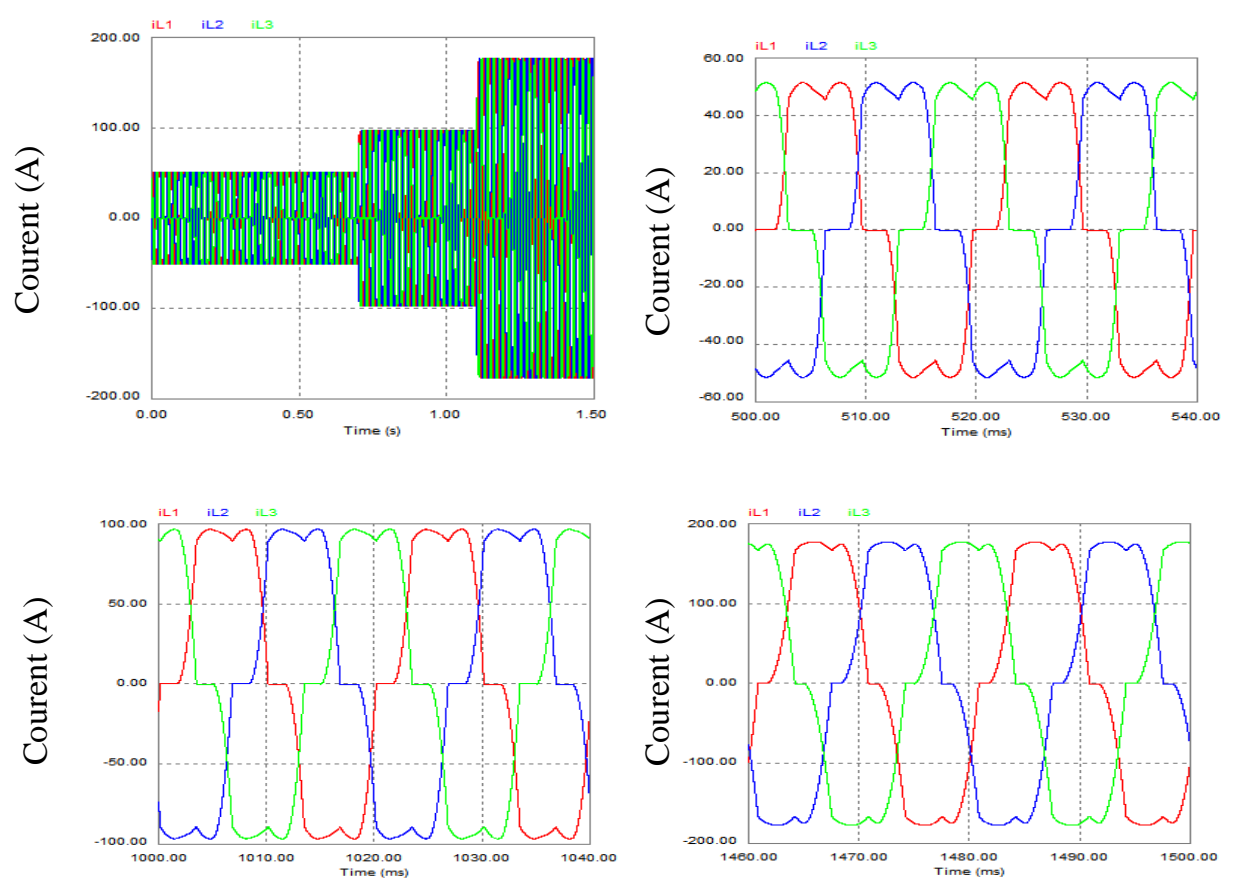

Figure 6. Three-phase current of the polluting load
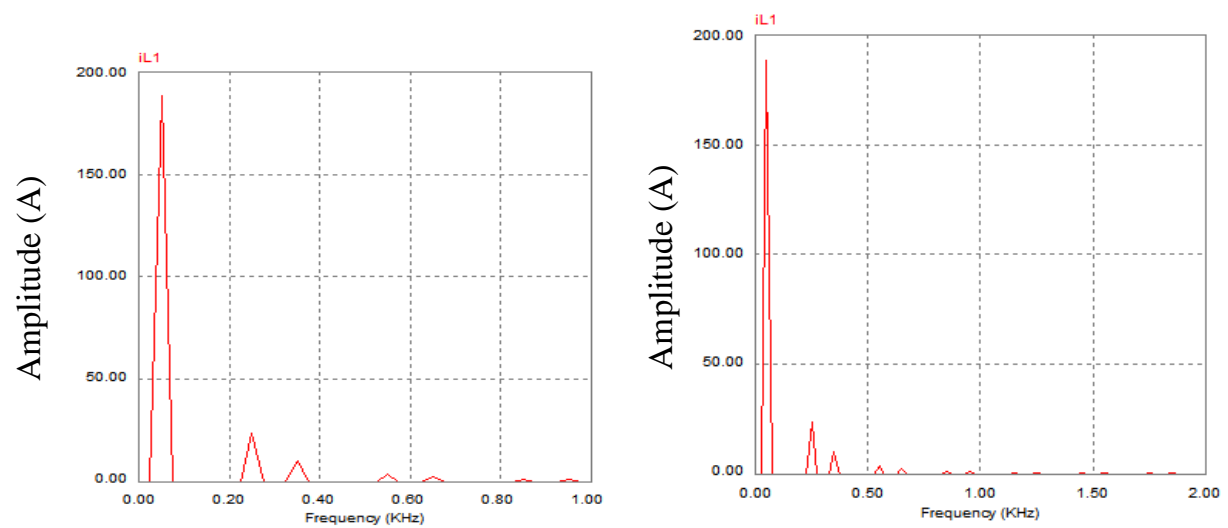

$\mathrm{t} \in[1.46,1.5] \mathrm{sec}$ 

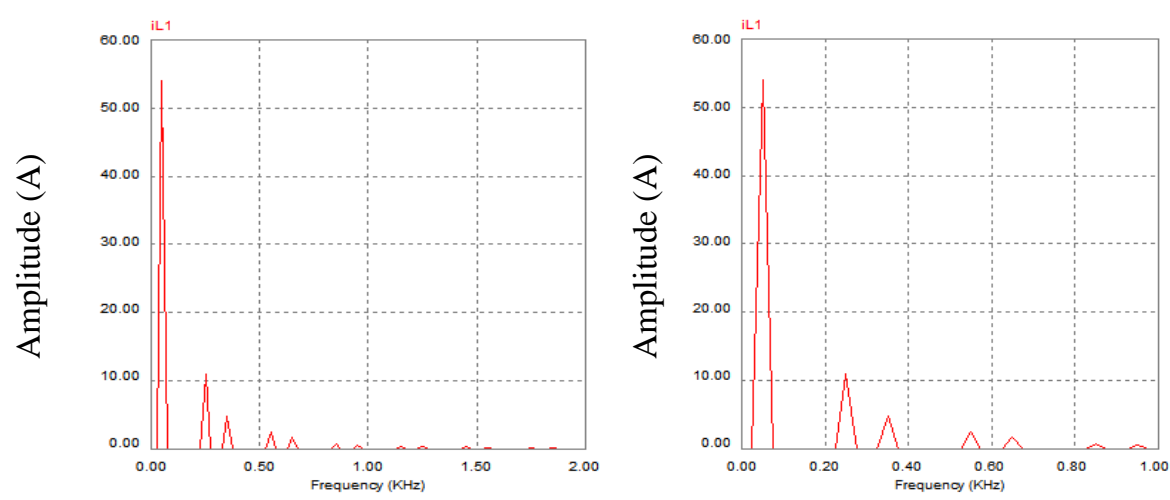

$\mathrm{t} \in[0.5,0.54] \mathrm{sec}$

Figure 7. Spectral analysis of the phase 1 current of the pollutant load

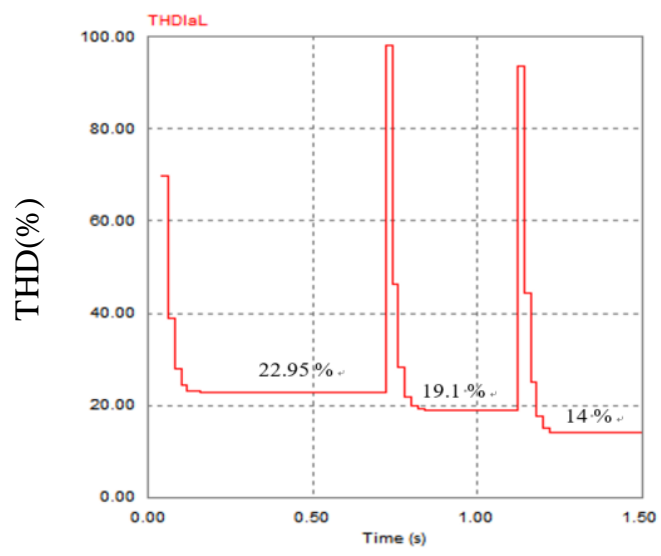

Figure 8. Evolution of the harmonic distortion rate (THD) of the phase 1 current of the polluting load
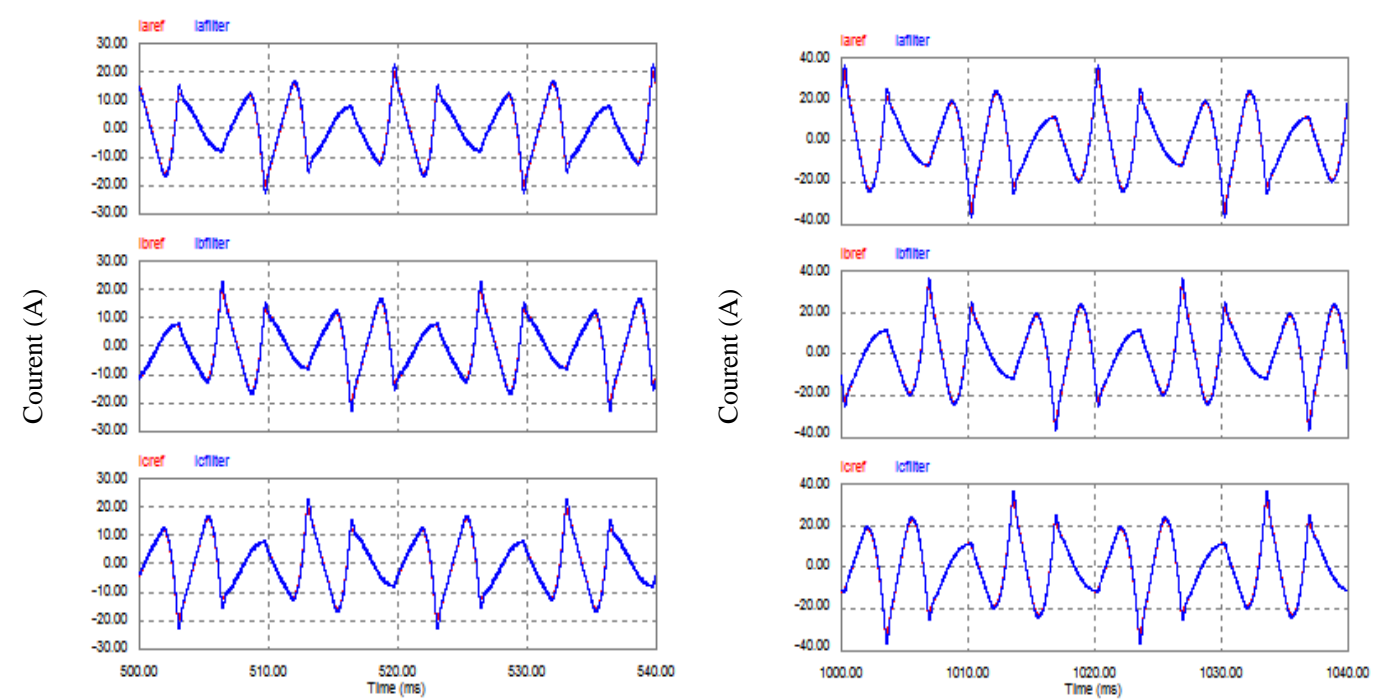


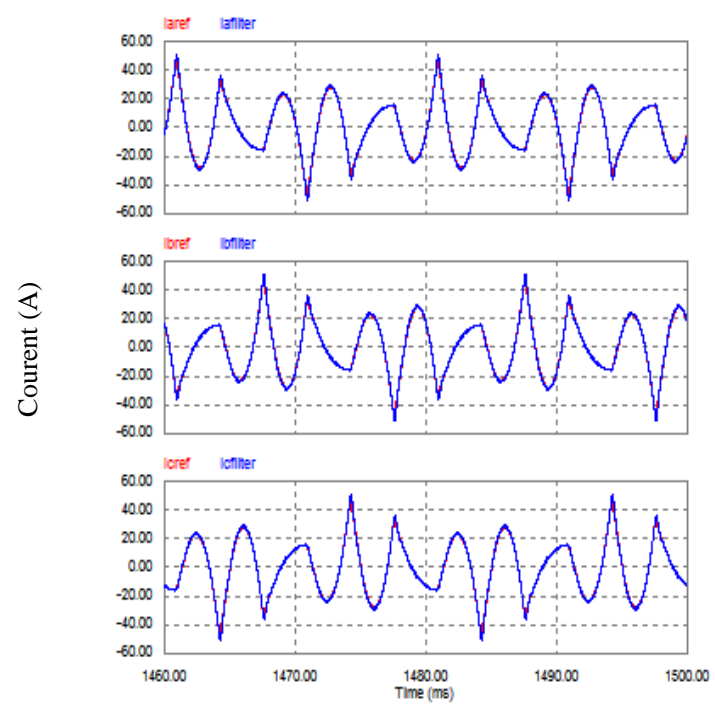

Figure 9. Three-phase harmonic current identified by the instantaneous real and imaginary powers method and three-phase current injected by the voltage-converter-based APF at 5 levels
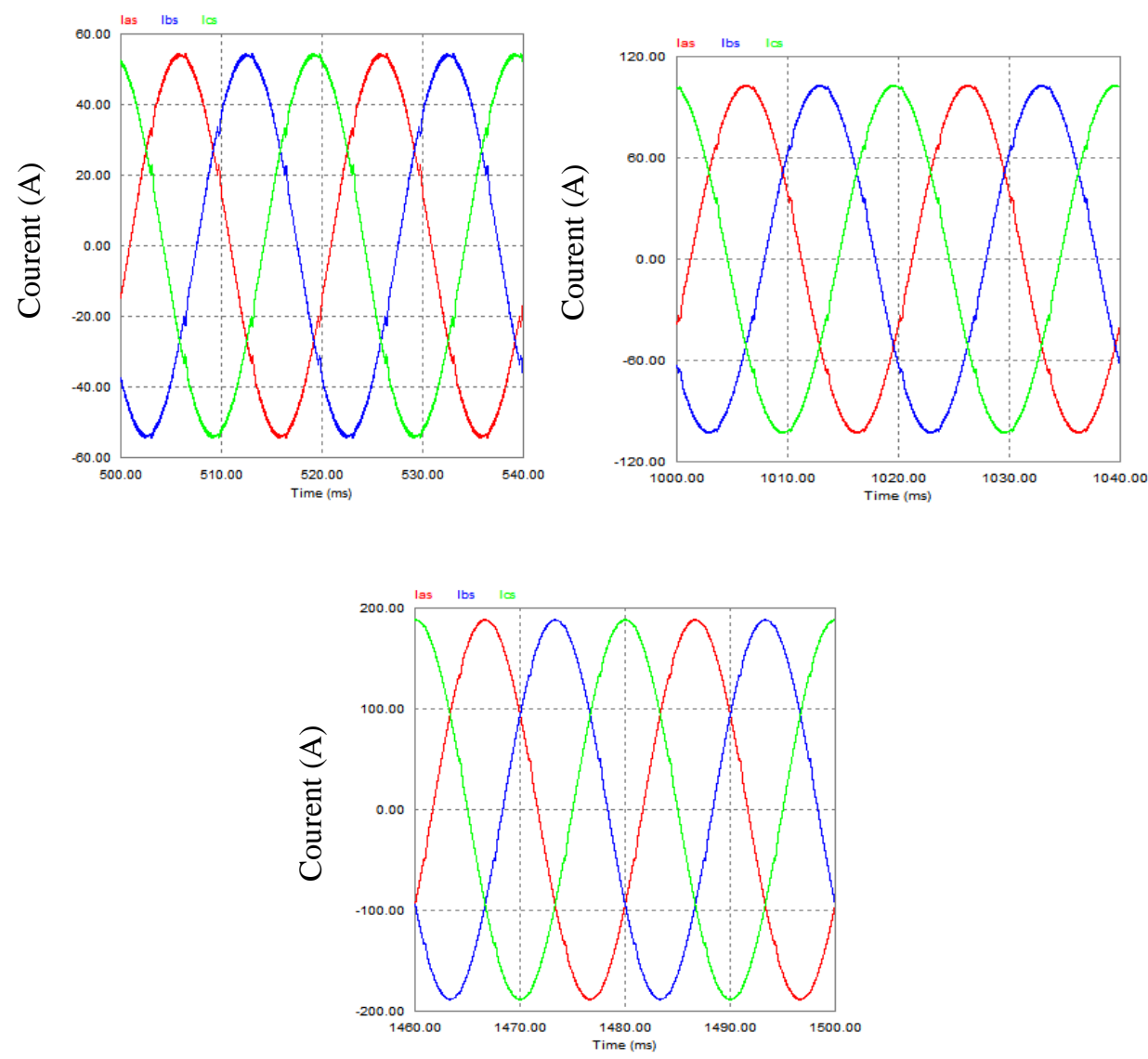

Figure 10. Three-phase power of the electrical network after filtering by an AFP based on 5-level voltage inverter 

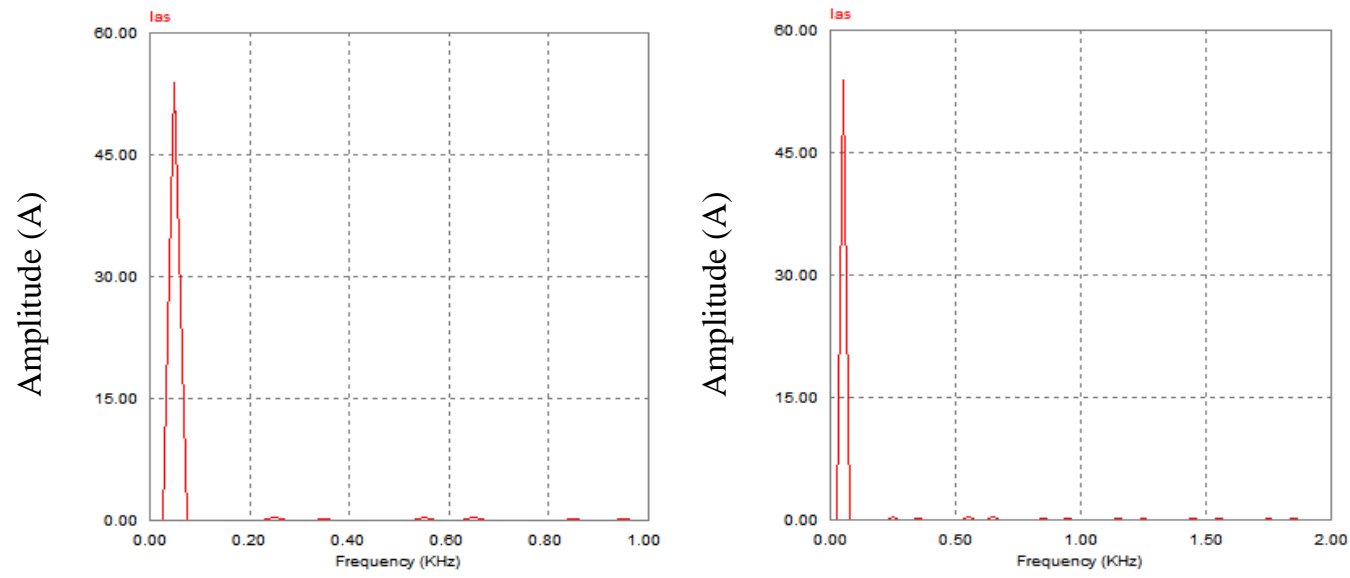

$\mathrm{t} \in[0.5,0.54] \mathrm{sec}$
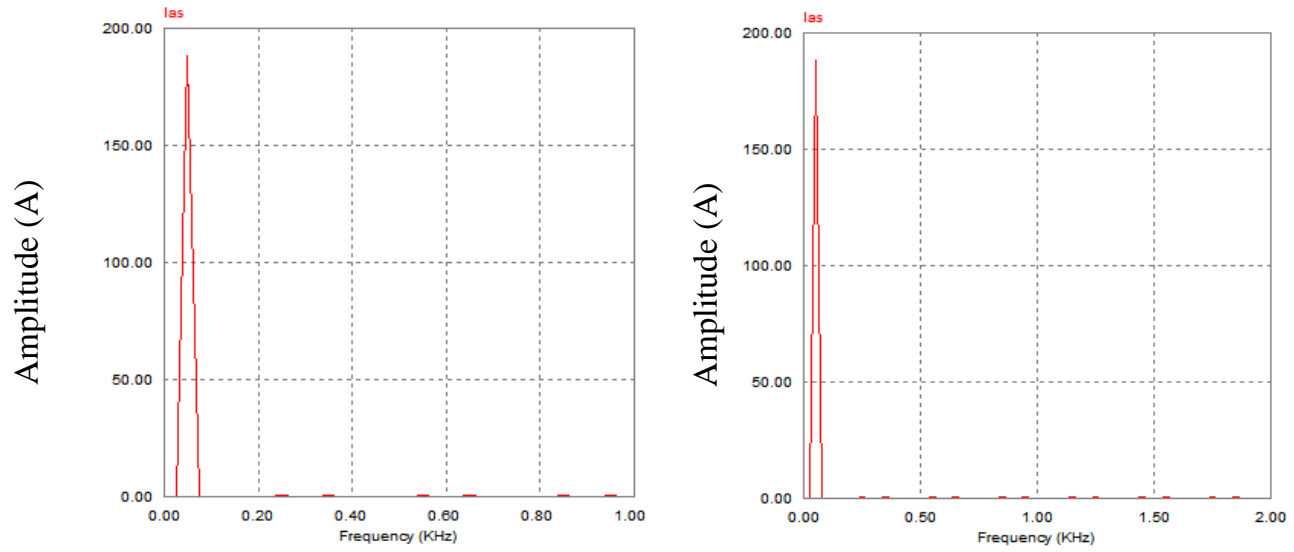

$\mathrm{t} \in[1.46,1.5] \mathrm{sec}$

Figure 11. Spectral analysis of the current of the phase 1 of the electrical network after filtering by an APF based on 5-level voltage inverter

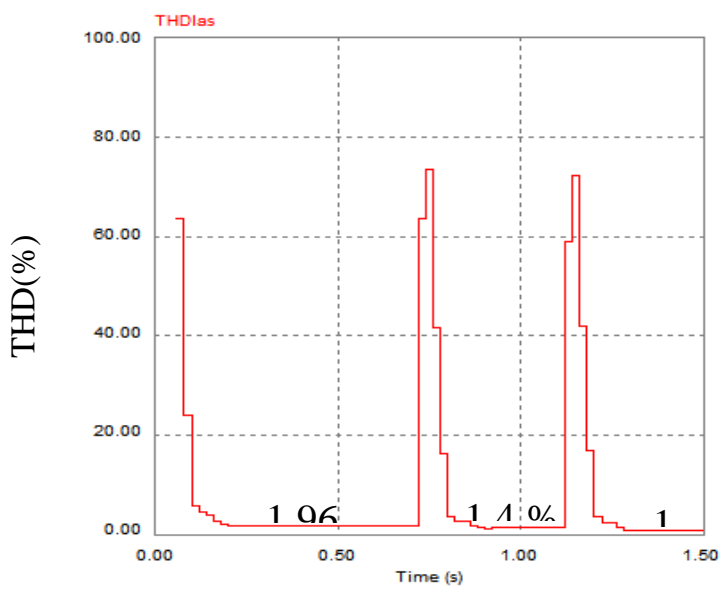

Figure 12. Evolution of the harmonic distortion rate (THD) of the current of phase 1 of the electrical network after filtering by an APF based on 5-level voltage inverter, $\mathrm{Vp}=5 \mathrm{Khz}$ 


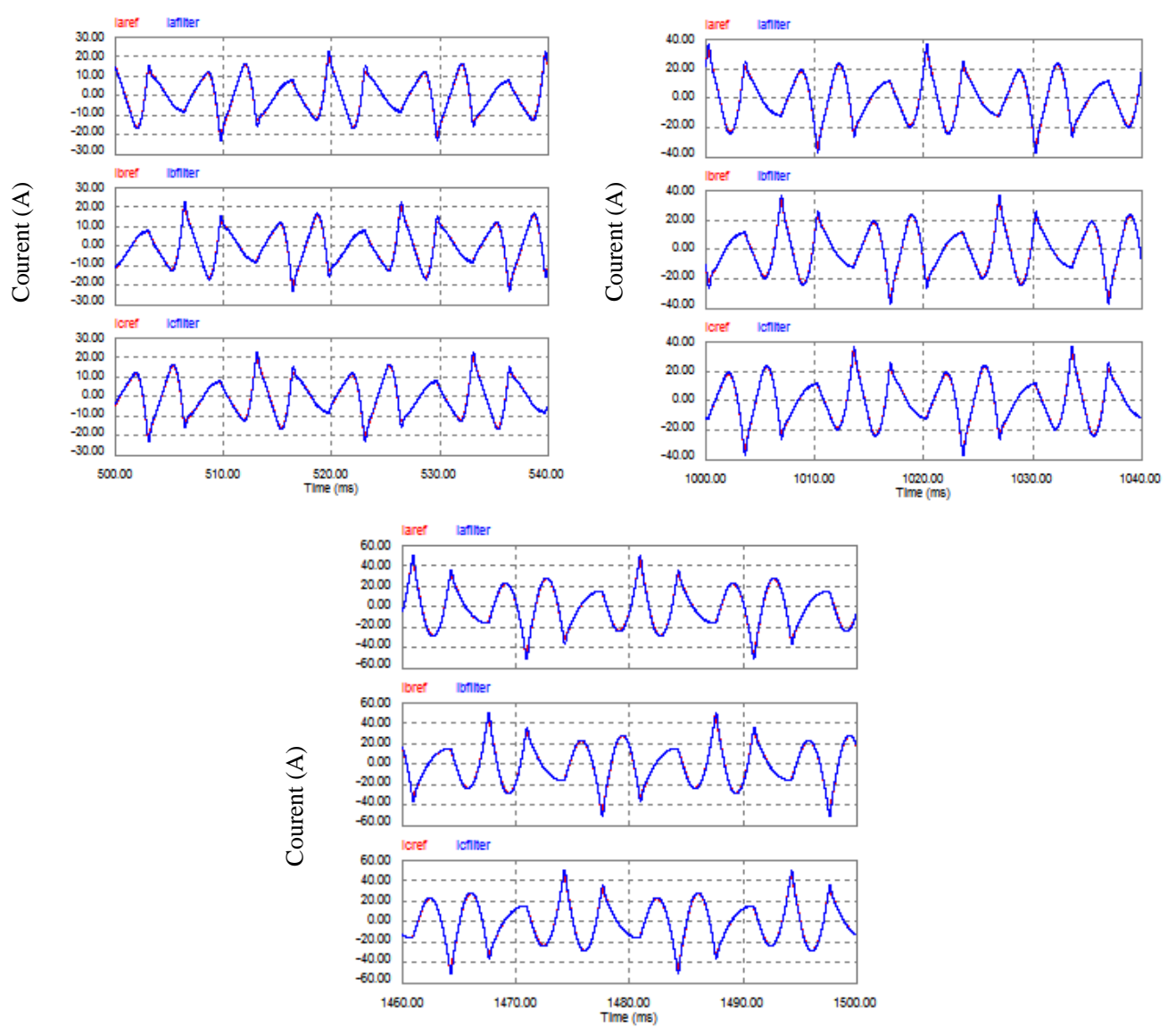

Figure 13. Three-phase harmonic current identified by the instantaneous real and imaginary power method and three-phase current injected by the voltage-converter-based APF at 7 levels
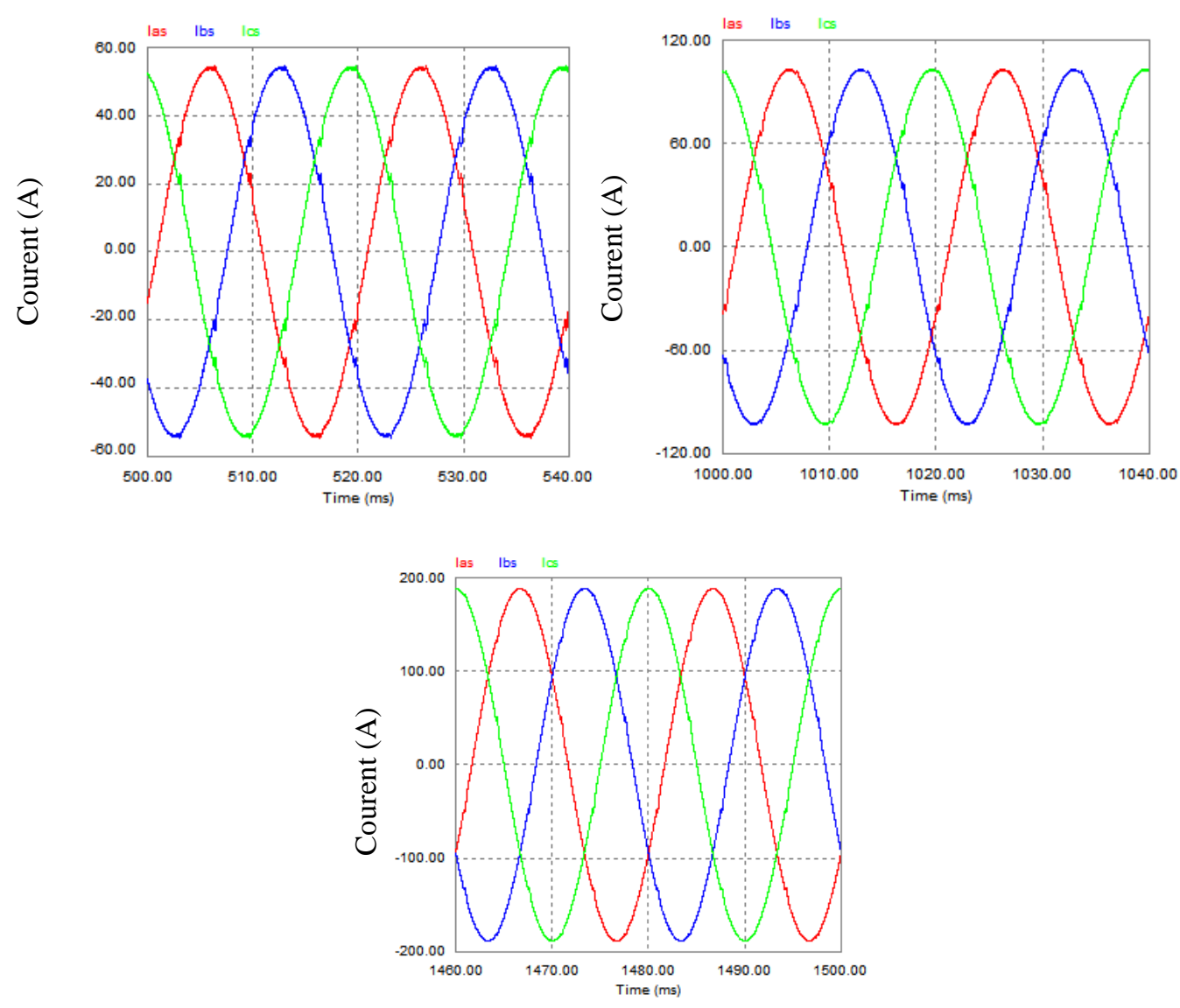

Figure 14. Three-phase mains power after filtering by a 7-level voltage inverter-based APF 

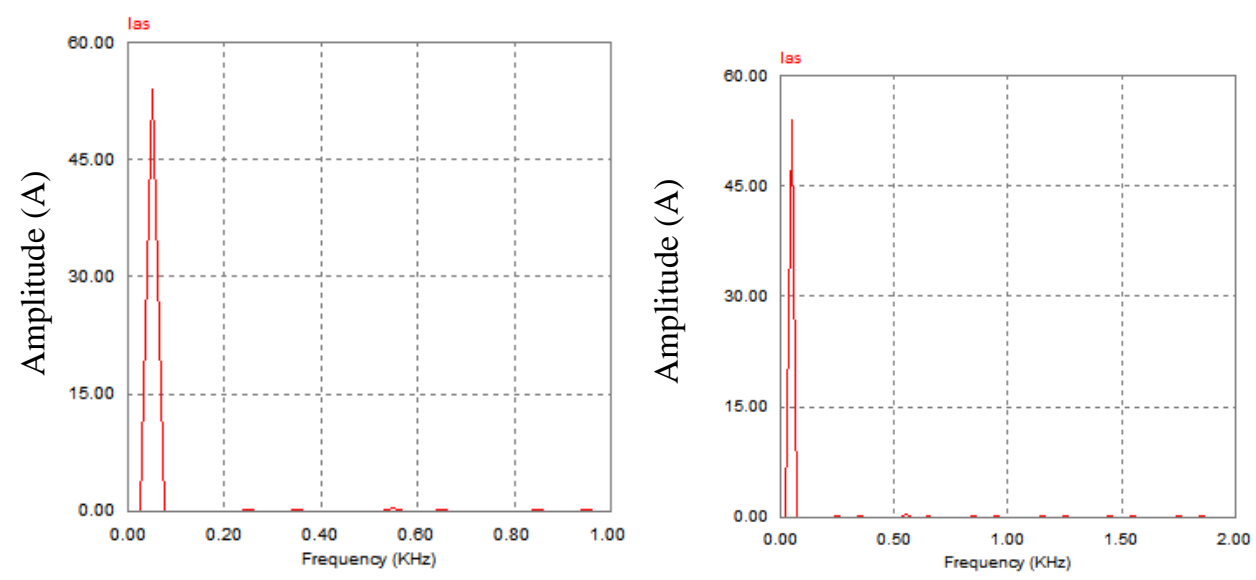

$\mathrm{t} \in[0.5,0.54] \mathrm{sec}$
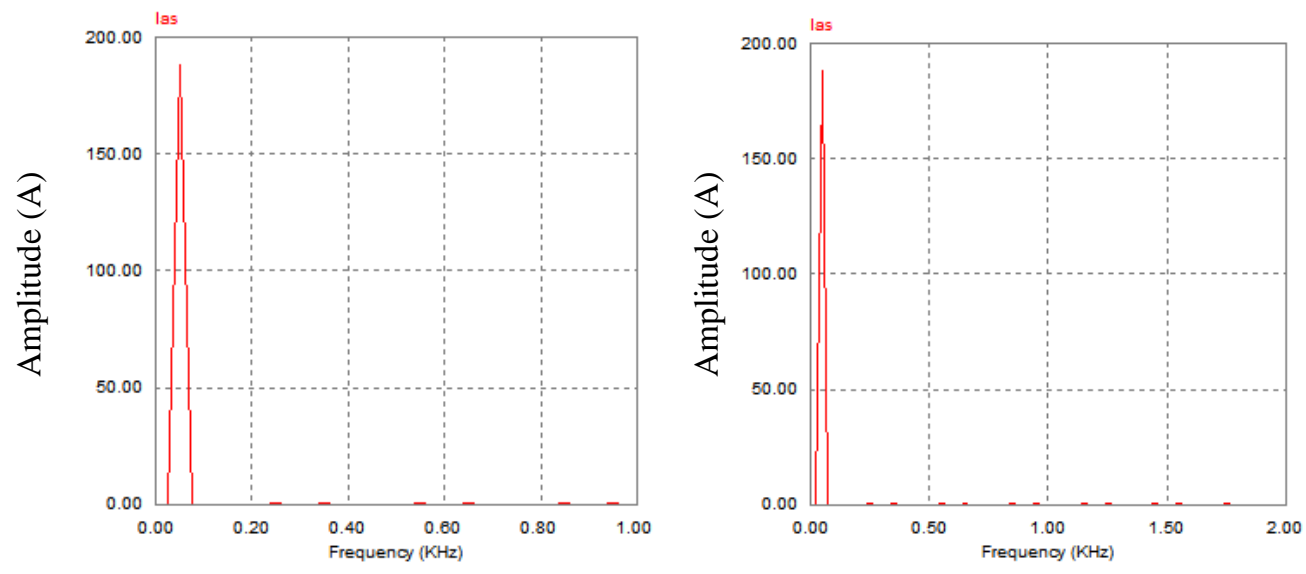

$\mathrm{t} \in[1.46,1.5] \mathrm{sec}$

Figure 15. Spectral analysis of the current of the phase 1 of the electrical network after filtering by an APF based on 7-level voltage inverter

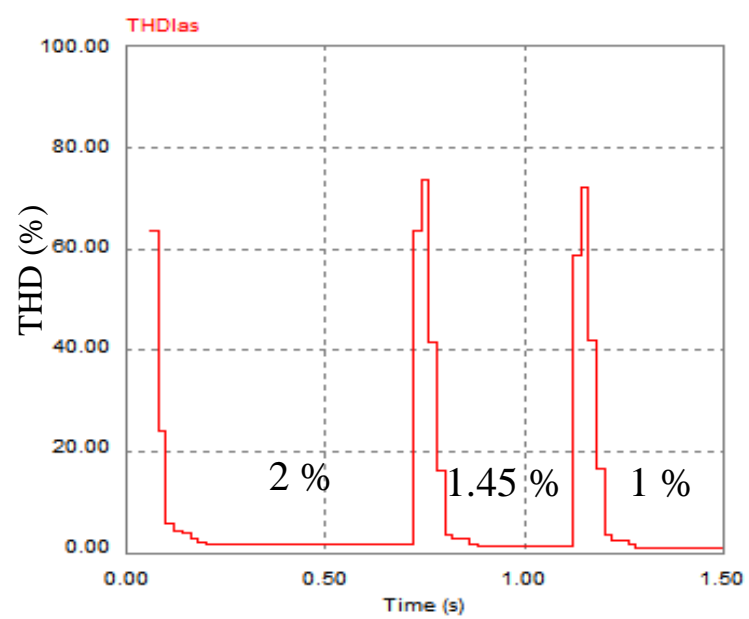

Figure 16. Evolution of the harmonic distortion rate (THD) of the current of the phase 1 of the electrical network after filtering by an APF based on 7-level voltage inverter, $\mathrm{Vp}=2,5 \mathrm{Khz}$ 


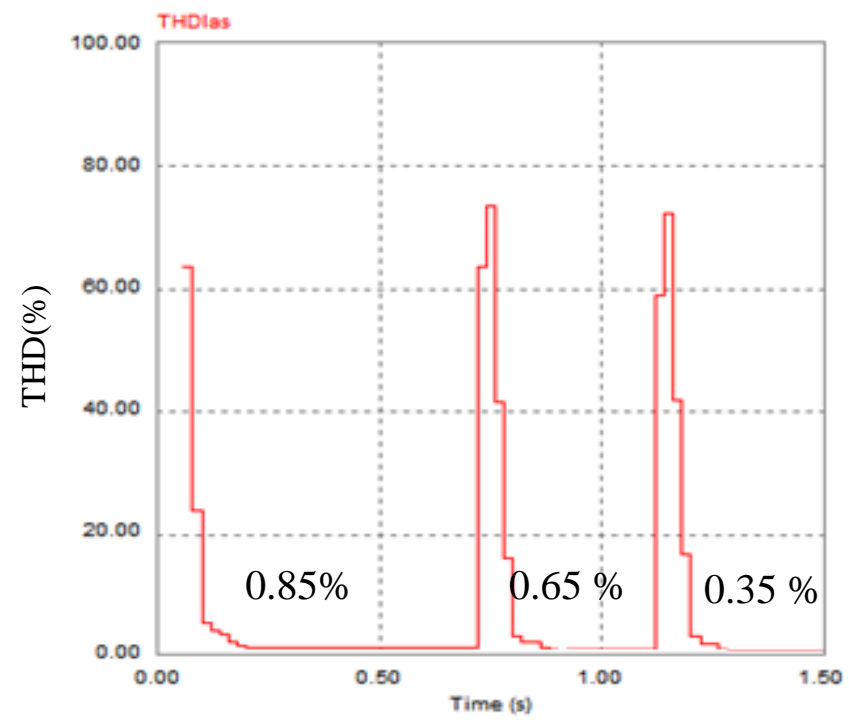

Figure 17. Evolution of the harmonic distortion rate (THD) of the current of phase 1 of the electrical network after filtering by an APF based on 7-level voltage inverter, $\mathrm{Vp}=5 \mathrm{Khz}$

\section{DISCUSSIONS}

The table below present the summary results of the different simulations obtained for the direct control strategy applied to the topologies of active power filter has 2,5 and 7-level inverter.

- The results obtained showed the improvement of the quality of the filtering by increasing in number of levels of the voltage inverter with possibility of reduction of the switching frequency

- Comparing the results obtained using a PWM 7-level voltage inverter-based APF with a carrier frequency of 2.5 $\mathrm{kHz}$ with that of the PWM 5-level voltage inverter-based APF with carrier frequency of $5 \mathrm{kHz}$, it can be concluded that the THD of the source current could be reduced to less than $2 \%$ but with half the switching frequency.

Table 2. Summary of the results of the different simulations obtained for the PWM control strategy applied to topologies (2,5 and 7) of active parallel filter

\begin{tabular}{|c|c|c|}
\hline APF / 2-level Voltage Inverter & APF / 5-level Voltage Inverter & APF / 7-level Voltage Inverter \\
\hline & & $\mathrm{Vp}=5 \mathrm{Khz}$ \\
$\mathrm{Vp}=5 \mathrm{Khz}$ & $\mathrm{Vp}=5 \mathrm{Khz}$ & $\mathrm{THD}=<1 \%$ \\
$2 \%<\mathrm{THD}<4 \%$ & $\mathrm{THD}<2 \%$ & $\mathrm{Vp}=2,5 \mathrm{Khz}$ \\
& & $\mathrm{THD}<2 \%$ \\
\hline
\end{tabular}

\section{CONCLUSION}

In this paper, five level and seven level cascaded H-bridge inverters have been simulated by using PSIM. The results of simulated system of multilevel Cascaded $\mathrm{H}$ - Bridge inverter have been compared on the basis of different parameters such as number of switches, number of DC sources required for operation and THD levels. According to the comparison, the seven level inverter has les THD level as compared to the fivelevel. From this comparison, we can conclude that as the number of level increases the THD level decreases. As the Hbridges increases the harmonic content in the output of inverter decreases for the same carrier frequency.

\section{REFERENCES}

[1] Bouhali O, Berkouk EM, Saudemont C, François B. (2004). A five level diode clamped inverter with selfstabilization of the DC-link voltage for grid connection of distributed generators. IEEE International Symposium on Industrial Electronics: ISIE 2004, Ajaccio, France 2: 947-952. https://doi.org/10.1109/ISIE.2004.1571941

[2] Nabae A, Takahashi I, Akagi H. (1980). A new neutral clamped PWM inverter. IEEE Transactions on Industry Applications IA-17(5): 518-523. https://doi.org/10.1109/TIA.1981.4503992

[3] Manguelle JS. (2004). Asymmetric multilevel converters powered by low frequency multi-frequency transformers: reactions to the supply network. Ph.D. Thesis, Swiss Federal Institute of Technology Lausanne, Switzerland.

[4] Foch H, Forest F, Meynard T. (1997). Voltage inverters: structures, principles, applications. Engineering Techniques, Electrical Engineering Treaty (D3): 176.

[5] Massoud AM, Finney SJ, Cruden AJ, Williams BW. (2007). Three-phase, three wire, five-level cascaded shunt active filter for power conditioning, using two different space vector modulation techniques. IEEE Trans. Power Del. 22(4): 2349-2361. https://doi.org/10.1109/tpwrd.2007.905447 
[6] Zhang H, Finney SJ, Massoud A, Williams BW. (2008). An SVM algorithm to balance the capacitor voltages of the three-level NPC active power filter. IEEE Trans. Power Electron. 23(6): 2694-2702. https://doi.org/10.1109/tpel.2008.2002820

[7] Xiao P, Venayaga moorthy GK, Corzine KA. (2009). Seven-level shunt active power filter for high-power drive systems. IEEE Trans. Power Electron 24(1): 6-13. https://doi.org/10.1109/tpel.2008.2005897

[8] Li J. (2010). Design, control and characteristics of multilevel active NPC converters for high power applications. $\mathrm{PhD}$ thesis of North Carolina State University.

[9] Benyettou L, Benslimane T, Bentata K, Abdelkhalek O. (2015). Open transistor faults characterization novel method for cascaded h-bridge five-level three-phase shunt active power filter. AMSE Journals, Modelling A 88(1): 53-70.

[10] Loutfi B, Tarak B, Khadija B. (2014). Faults diagnosis in cascaded h-bridge seven-level shunt active power filter. The Mediterranean Journal of Measurement and Control 10(4): 300-308.

[11] Akagi H, Kanazawa Y, Nabae A. (1983). Generalized theory of the instantaneous reactive power filter. Proceedings of International power electronics conference, Tokyo, Japan: 1375-1386.

[12] Benslimane T, Aliouane K. (2004). A new optimized SVPWM technique control for autonomous parallel active filter. 11th International Conference on Harmonics and Quality of Power. - New York, USA, IEEE Xplore, IEEE Transactions on Automatic Control: 112-116. https://doi.org/10.1109/ICHQP.2004.1409338

[13] Nabae A, Takahashi I, Akagi H. (1981). A new neutral point clamped PWM inverter. IEEE Transactions on Industry Applications IA-17(5): 518-523. https://doi.org/10.1109/tia.1981.4503992

[14] Thongprasri P. (2011). A 5-level three-phase cascaded hybrid multilevel inverter. International Journal of Computer and Electrical Engineering 3(6): 789-794. 